\title{
Review
}

Ann Nutr Metab 1991;35:249-252

(C) 1991 S. Karger AG, Basel 0250-6807/91/0355-0249\$2.75/0

\section{Biological Markers of Dietary Intake, with Emphasis on Fatty Acids}

\author{
Martijn B. Katan a, Angélique van Birgelen ${ }^{\mathrm{a}}$, Jean Paul Deslypere ${ }^{\mathrm{b}}$, Margriet Penders ${ }^{\mathrm{a}}$, \\ Wija A. van Staveren ${ }^{\text {a }}$ \\ a Department of Human Nutrition, Wageningen Agricultural University, The Netherlands; \\ ${ }^{b}$ Department of Endocrinology and Hematology, State University of Ghent, Belgium
}

Key Words. Diet $\cdot$ Methodology $\cdot$ Polyunsaturated fatty acids

Abstract. The level of certain polyunsaturated fatty acids in body fluids or tissues can be a valid indicator of their consumption in man. In 59 housewives studied over a 2.5-year period we found a correlation of 0.70 between the intake of linoleic acid, assessed as the mean of nineteen 24-hour recalls, and the level in fat tissue [Van Staveren et al.: Am J Epidemiol 1986;123:455-465]. In 58 adult men supplemented with fish oil capsules for 1 year, the rise of eicosapentaenoic acid levels in erythrocyte membranes was strongly and specifically related to the rise in intake. We conclude that epidemiological studies of the role of these fatty acids in health and disease could fruitfully employ these markers of dietary intake.

\section{Introduction}

The lack of accurate and reproducible methods for the assessment of nutrient intake is a major obstacle for research on the relation between diet and health. For that reason there is much interest in objective biochemical parameters that reflect dietary intake. The more successful markers developed hitherto [1] are those for protein (via urinary nitrogen), energy (via the doublelabeled water technique), sodium and potassium (urinary excretion), and markers for the intake of various fatty acids. The essen- tial $(n-6)$ polyunsaturated fatty acid linoleic acid has been studied most. The content of this fatty acid in various fractions reflects a moving average of the intake over preceding periods of time of various length. Thus the linoleic acid content of cholesteryl esters in blood serum reflects the diet of the preceding weeks and that of erythrocyte membranes that of the preceding 2-3 months, while the linoleic acid content of microbiopsies of subcutaneous fat tissue faithfully reflects individual consumption over the preceding 1-3 years. All these parameters can now be measured routinely in epidemiological studies. 


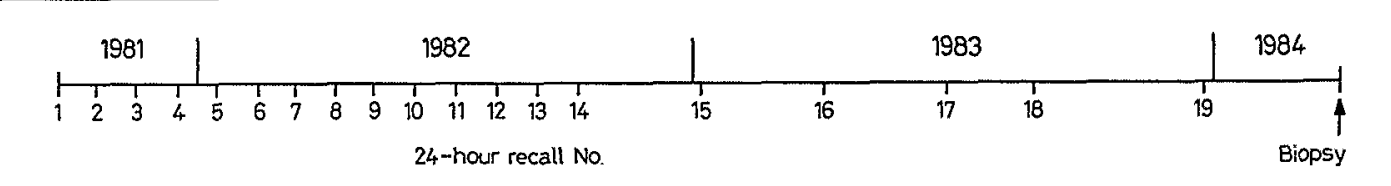

Fig. 1. Design of the study on linoleic acid in fat tissue biopsies as an indicator of intake.

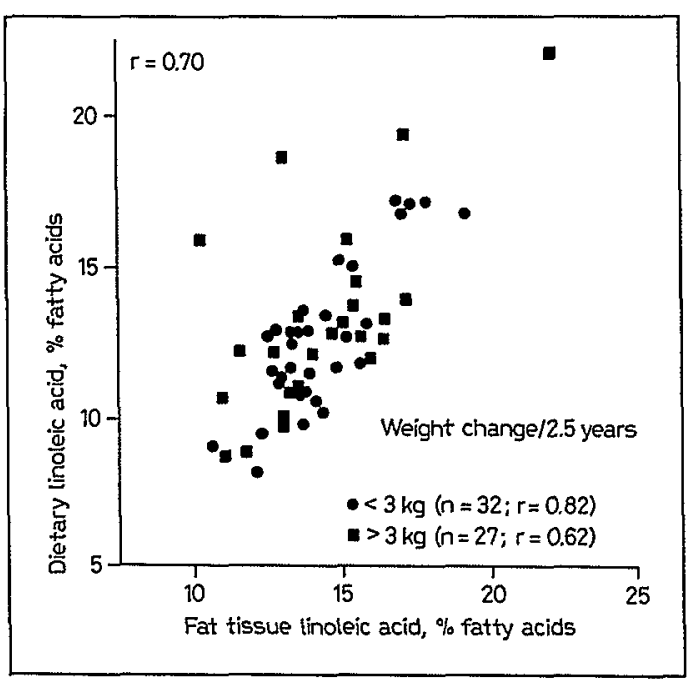

Fig. 2. Correlation between linoleic acid in the diet, assessed as the mean of 19 recalls per subject (see fig. 1), and linoleic acid in subcutaneous fat in 59 Dutch women. Separate data are given for those women whose body weight fluctuated by more than $3 \mathrm{~kg}$ over the duration of the study ( $(\omega)$, and those subjects whose body weight was more stable $(\bullet)$.

Recently we have turned our attention to markers for other fatty acids, including the $(n-3)$ polyunsaturated fatty acids ( $\omega 3$-fatty acids) typically found in marine oils. Here we review some of our experience with linoleic acid in adipose tissue as a marker of long-term intake, and we present some preliminary data on the $(n-3)$ polyunsaturates.

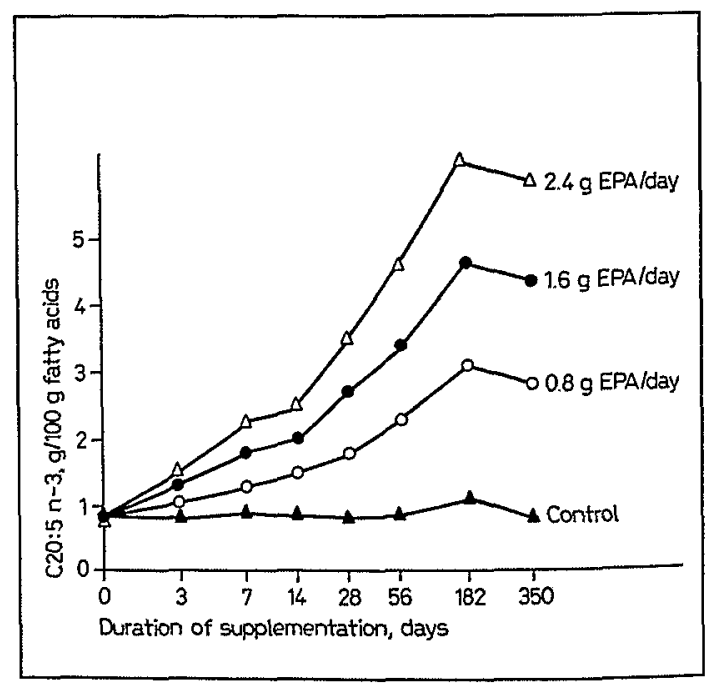

Fig. 3. Level of EPA (C20:5 n-3) in blood erythrocyte lipids as a function of duration and level of supplementation. All subjects received 9 capsules of oil/day; out of these, either 0 (control), 3, 6 or all 9 contained fish oil, and the other capsules a placebo oil mixture with the same content of saturated fatty acids, linoleic acid, vitamin $\mathrm{E}$ and cholesterol as the fish oil. Amounts of EPA provided by the capsules are indicated in the figure.

\section{Methods and Results}

The study on linoleic acid in adipose tissue has been described in detail [2]. Figure 1 presents the design. Briefly, 59 housewives living in the town of Renkum were each questioned about their dietary intake 19 times over the course of a 2.5 -year period 
using the 24-hour recall method. Subsequently, a single microbiopsy of subcutaneous fat was obtained from the buttock in each of them [3]. As shown in figure 2, there was a strong correlation between the individual values for the intake of linoleic acid and for the proportion in the subcutaneous fat tissue. The intake was assessed as the mean of all 19 recalls performed in each subject. If only a single 24-hour recall was used to assess intake - a very common procedure in studies on dietary determinants of disease then the correlation fell to 0.28 . The reason for this difference is well known [4]: a person's intake on a particular day is not at all representative of that person's long-term intake. As a result, many of the intake values obtained by a single recall are grossly in error if the long-term intake is the variable on which information is being sought.

Over the past 5-10 years, major advances have been made in the technique of capillary gas chromatography. As a result it is now possible to assay the proportion of the highly unsaturated very-long-chain polyunsaturated fatty acid, eicosapentaenoic acid (also known as EPA, timnodonic acid, or C20:5 $\mathrm{n}-3$ ) in biological samples with great accuracy and reproducibility [5].

Due to the lack of food table data, and the variability of the EPA content in fish, we considered it impossible to obtain reliable estimates of EPA intake by survey in the manner used for linoleic acid above. We have therefore investigated the potential of EPA in blood cells as an indicator of intake by feeding volunteers known amounts of fish oil, and monitoring the rise in EPA in erythrocyte lipids. As shown in figure 3 , the amount of EPA supplemented is indeed reflected in the proportion of EPA in the erythrocytes. Equilibrium values were reached be- tween 2 and 6 months after initiation of supplementation. (The slightly higher value at 6 than at 12 months was caused by a temporary, unscheduled increase in fish intake in the volunteers during the 6 th month.) It can be calculated that each increase in erythrocyte EPA by $2 \mathrm{~g} / 100 \mathrm{~g}$ fatty acids would reflect an increase in intake by $3.20 \pm 0.13 \mathrm{~g} /$ day (mean $\pm \mathrm{SE}$ ) over the past 7 days or by 1.24 $\pm 0.10 \mathrm{~g} /$ day over the past few months.

\section{Conclusions}

Our data on linoleic acid are in good agreement with those of other workers. They suggest that the adipose tissue content of linoleic acid is a more reliable indicator of a subject's long-term exposure to dietary linoleic acid than the intake as assessed by a single 24-hour dietary recall.

The data on EPA are encouraging, and suggest new ways to study the relation between exposure to the 'fish fatty acids' - and the occurrence of disease. However, more studies are needed before we can be confident that the relation found between EPA intake and erythrocyte EPA levels in the present experiment will also hold for those populations of interest to epidemiologists.

\section{Acknowledgements}

We are greatly indebted to our volunteers in Renkum and to the Brothers in Egmond, Oosterhout, Vaals, and Zundert for the selflessness and dedication with which they participated in these studies. In addition we are grateful to Jan Burema, MSc, Ans Soffers, Petra ter Wal, Joke Korevaar, and Magda Hectors for their contribution to these investigations, and to the Praeventie-fonds, The Hague, The Netherlands and Sanofi-Labaz, Belgium for funding. 


\section{References}

1 Bingham SA: Limitations of the various methods for collecting dietary intake data. Ann Nutr Metab 1991;35:117-127.

2 Van Staveren WA, Deurenberg P, Katan MB, Burema J, de Groot CPGM, Hoffmans MDAF: Validity of the fatty acid composition of subcutaneous fat tissue microbiopsies as an estimate of the long-term average fatty acid composition of the diet of separate individuals. Am J Epidemiol 1986;123:455-463.

3 Beynen AC, Katan MB: Rapid sampling and longterm storage of subcutaneous adipose-tissue biopsies for determination of fatty acid composition. Am J Clin Nutr 1985;42:317-322.
4 Cameron ME, van Staveren WA: Manual on methodology for food consumption studies. Oxford Medical Publications. London, Oxford University Press, 1988.

5 Katan MB, van de Bovenkamp P: Eicosapentaenoic acid in fat. Lancet 1987;i:862-863.

Martijn B. Katan

Professor of Human Nutrition

Department of Human Nutrition

Wageningen Agricultural University

PO Box 8129

$6700 \mathrm{EV}$ Wageningen (The Netherlands) 